\title{
Identification of noncompliant glaucoma patients using Bayesian networks and the Eye-Drop Satisfaction Questionnaire
}

This article was published in the following Dove Press journal:

Clinical Ophthalmology

7 December 2010

Number of times this article has been viewed

\author{
Jean-Philippe Nordmann' \\ Christian Baudouin' \\ Jean-Paul Renard ${ }^{2}$ \\ Philippe Denis ${ }^{3}$ \\ Antoine Regnault ${ }^{4}$ \\ Gilles Berdeaux ${ }^{5,6}$ \\ 'Hôpital des Quinzes-Vingt, Paris; \\ ${ }^{2}$ Hôpital du Val de Grâce, Paris; \\ ${ }^{3}$ Hôpital Edouard Herriot, Lyon; \\ ${ }^{4}$ Mapi Values, Lyon; ${ }^{5}$ Alcon France, \\ Rueil-Malmaison; ${ }^{6}$ Conservatoire \\ National des Arts et Métiers, \\ Paris, France
}

Objective: To identify poorly compliant glaucoma patients, using the Eye-Drop Satisfaction Questionnaire (EDSQ).

Methods: This was an observational cross-sectional study with compliance data collected by an electronic monitoring device. Patients with primary open-angle glaucoma or ocular hypertension completed the EDSQ, a six-dimension self-reported questionnaire addressing "treatment concern", "disease concern", "patient-clinician relationship", "positive beliefs", "treatment convenience", and "self-declared compliance". A Bayesian network (BN) was applied to explore compliance associations with EDSQ.

Results: Among 169 patients who completed the EDSQ, 113 had valid Travalert ${ }^{\circledR}$ data, of whom 25 (22.1\%) demonstrated low compliance. All six EDSQ dimensions were associated directly, or indirectly, with compliance. Two profiles exhibited low compliance, ie, patients aged younger than 77.5 years with a poor patient-physician relationship and self-declared poor compliance and patients aged older than 77.5 years with a poor patient-physician relationship and self-declared good compliance. The third profile showed high compliance, ie, patients aged younger than 77.5 years with a good patient-physician relationship and self-declared good compliance.

Conclusion: Our results confirm a central role for the patient-physician relationship in the compliance process. Age, self-declared compliance, and patient satisfaction with the patientphysician relationship are all dimensions worth exploring before glaucoma medication is switched or proceeding to laser treatment or surgery.

Keywords: glaucoma, compliance, risk factors, patient satisfaction

\section{Introduction}

Glaucoma is the second leading cause of blindness globally. ${ }^{1}$ From 1991 to 1999 , primary open-angle glaucoma prevalence increased from $4.6 \%$ to $13.8 \%$ among the elderly. ${ }^{2}$ Its treatment is aimed essentially at lowering intraocular pressure (IOP) by eye drop instillations, reserving surgery or laser surgery for the most severe cases. Several classes of medicine are available, ie, prostaglandin analogs, miotics, beta-blockers, alpha-adrenergic agonists, and carbonic anhydrase inhibitors. Glaucoma treatment principles and options have been reported by the European Glaucoma Society. ${ }^{3}$ Successful treatment depends upon strict lifetime adherence to the instillation schedule. Thus, higher adherence is associated with better IOP control, on average, ${ }^{4}$ and a lower risk of eventual blindness. ${ }^{5}$ However, patients perceive few symptoms in the early stages, whereas eye drops (with potential side effects) are needed daily and may become a burden, leading to poor treatment adherence. ${ }^{6}$
Correspondence: Gilles Berdeaux Alcon France, 4 rue Henri Sainte-Claire Deville, 92563 Rueil-Malmaison Cedex, France

Tel +330147104860

Fax +3347102770

Email gilles.berdeaux@alconlabs.com 
Adherence to treatment schedules has been examined by numerous studies in glaucoma, using various methods. For example, the medication possession ratio, determining the mean proportion of days during a given period when patients possess medication, was calculated from insurance claims or prescription databases, ${ }^{7-9}$ and from electronic devices capturing drop counts. ${ }^{10}$ Alternatively, patients' self-declared compliance was obtained from interviews ${ }^{11-13}$ or standardized questionnaires. ${ }^{8,14-18}$ Another difference between studies were noncompliance criteria, eg, patients who missed more than two doses per week ${ }^{18}$ or possessed insufficient drops for the specified period (medication possession ratio $<1$ ). ${ }^{5}$ With this array of methodology across different drug classes and countries, compliance rates varied from 59\% to 77\% . $^{7,11,14,16,18-21}$ More informally, imperfect compliance is consistently reported among glaucoma patients.

To improve glaucoma care, it is critical to identify patients who may not adhere to treatment. Factors conducive to noncompliance have been explored. For example, complex dosing regimens have an impact on compliance. ${ }^{19,22}$ However, barriers cited by most studies relate to patients' perception and knowledge about their illness and its treatment. ${ }^{7,11,16,18}$ These considerations prompted the development of an Eye-Drop Satisfaction Questionnaire (EDSQ) which asks patients to self-report their satisfaction and compliance with topical ophthalmic treatments. ${ }^{23}$ Replies to these questions should be relevant to an exploration of noncompliance in glaucoma patients.

A suitable technique for analyzing such data is a Bayesian network $(\mathrm{BN})$ which facilitates the representation and manipulation of information. A BN is a directed acyclic graph representing relationships between variables (nodes in the graph) with a related set of conditional probability tables that characterize local dependencies between the various nodes. Hence, it provides a powerful tool to study interdependencies between complex processes, such as patient behavior. The objective of this study was to identify poorly compliant glaucoma patients by exploring EDSQ data.

\section{Methods and materials}

The present survey was conducted according to French law. The protocol was reviewed and approved by the Comité consultatif sur le traitement de l'information en matière de recherche dans le domaine de la santé and the Commission nationale informatique et liberté. ${ }^{24-26}$ This research was conducted according to the tenets of the Declaration of Helsinki. ${ }^{27}$

\section{Patients and study design}

This multicenter study was conducted in France by 17 ophthalmologists (at 17 sites) specializing in the treatment of glaucoma, who also prescribed Travalert ${ }^{\circledR}$, a computerized device that reminds patients to instill eye drops, assists with instillations, and records dosing times. The accuracy of Travalert for measuring treatment adherence has been described elsewhere. ${ }^{28,29}$ Ophthalmologists recruited patients who used the device and gave informed consent before participating. At the inclusion visit, the ophthalmologist completed a medical questionnaire for each patient. General comorbidities (cardiovascular, central nervous system, hepatic diseases, diabetes, pulmonary diseases, digestive diseases, others) and eye comorbidities (macular degeneration, diabetic retinopathy, retinal detachment, cataract, uveitis, others) were collected.

Patients included used the Travalert device for at least eight weeks, were 18 years of age or older, and diagnosed with either primary open-angle glaucoma (including juvenile glaucoma, exfoliative glaucoma, pigmentary glaucoma, or normal-tension glaucoma) or high IOP. Patients with secondary glaucoma (congenital glaucoma, inflammatory glaucoma, angle-closure or narrow-angle glaucoma following cataract surgery), or took an anticoagulant three times per day or more, and patients with chronic eye dryness requiring instillations of more than five drops a day, were excluded.

According to a previous clustering analysis, data collected with the Travalert device allowed the patient sample to be categorized according to three compliance profiles, ie, high compliance, moderate compliance, or low compliance. ${ }^{4}$

\section{Eye-Drop Satisfaction Questionnaire}

The EDSQ is a self-assessment questionnaire that assesses patient satisfaction and compliance with eye-drop treatment for glaucoma or IOP. Its development in France and the UK involved two steps. First, patient and clinician interviews were conducted to determine an appropriate conceptual model and obtain patients' ratings. Second, a comprehension evaluation was undertaken to ensure the questionnaire's clarity, ease of comprehension, and cultural equivalence. ${ }^{23}$ The questions are scored on a 1-5 Likert scale.

A scoring algorithm for the 21-item questionnaire was also developed and shown to have satisfactory validity and reliability. ${ }^{30}$ The EDSQ algorithm computes scores (0-100) for six dimensions of attitudes towards eye-drop treatment, ie, "treatment concern" (five items), "disease concern" (two items), satisfaction with the "patient-clinician relationship" (five items); "positive beliefs" (three items), "treatment 
convenience" (three items), and "self-declared compliance" (three items). High scores represented high dimension concerns.

EDSQ data were collected at the follow-up visit when the Travalert data were collected from the patient.

\section{Statistical analyses}

\section{Population analysis and oversampling strategy}

Patients who completed the EDSQ and provided sufficient Travalert data to define their compliance profile were included in the analysis. An oversampling method was adopted to increase the ability of the BN to identify risk factors for noncompliance. ${ }^{31}$ This involved randomly selecting patients from the smallest group (low compliance) as successive replacements to create a sample equal to the largest group (high and moderate compliance). A uniform (all patients had the same probability to be sampled, without site stratification) sampling method was used because the small sample size did not authorize strong distribution estimates. The objective was to achieve a ratio of one patient with low compliance to one with high or moderate compliance.

\section{Bayesian networks}

A BN is a form of probabilistic graph, representing a joint probability distribution of a set of variables with explicit independency assumptions. It is a directed acyclic graph, ie, without cycles and has edges that are orientated. It is composed of a set of nodes (each node represents one variable modeling the process of interest) and a set of conditional probability tables encoding local dependencies between the nodes/variables. BNs are often used to identify structure of the information when very few hypotheses could be identified a priori.

A BN was constructed to identify poor compliers by discriminating between low-compliance and moderate- or high-compliance patients. Center was not included in the BN due to the numbers of patients per center being too small. The network structure (relationships between variables) was based on data by applying the "taboo order" algorithm to scores derived from the BN learning algorithm. ${ }^{32}$ A score denoted the minimum description length, and was two fold; the first part qualified the network with respect to its structural complexity and the second part measured the goodness-offit between the network and the data. With a given order of nodes, it is simple to determine the best $\mathrm{BN}$, because each node looks to its best parent, ie, its immediate predecessor amongst all available nodes. The goal of taboo order is to search for the order of nodes resulting in the best $\mathrm{BN}$ value (highest minimum description length score), and to this end uses taboo search. ${ }^{33}$ This algorithm is fully driven by the data, is fully inferential, and with no clinical expert input. Missing data were inferred according to the expectation-maximization structural method. Because BN requires categoric variables, EDSQ scores were categorized by dichotomizing (thresholds were determined while estimating the $\mathrm{BN}$ ) them according to a decision tree-based algorithm aimed at maximizing the detection of low compliance. Descriptive analyses were performed using SAS for Windows v9.2 (SAS Institute, Inc., Cary, NC) and BN was obtained using Bayesialab v4.6.1 (Bayesia, Mayenne, France).

\section{Results}

Of the glaucoma specialists, $88.2 \%$ were male, $29.4 \%$ worked in a public hospital setting, and had qualified on average 16.5 years earlier. They declared 36.7 visits per week for primary open-angle glaucoma and 11.4 for ocular hypertension. Among 179 patients screened, 169 (94.4\%) completed the EDSQ at the visit. One hundred and forty patients (78.2\%) used the Travalert, brought it back to the visit, with successful data transfer to the investigator computer. Among the 140 transferred files, $113(80.7 \%)$ provided reliable data (compliance fully documented for at least eight weeks) sufficient for the classification algorithm. Technical criteria to participate to the clustering algorithm have been published elsewhere. ${ }^{4}$

\section{Patient characteristics}

The characteristics of patients meeting the inclusion criteria are presented in Table 1. The gender ratio was balanced, mean age was 65.1 years, $16.6 \%$ had undergone surgery for primary open-angle glaucoma, and $10.1 \%$ had received laser therapy. At the inclusion visit, worst eye mean IOP was $16.4 \mathrm{mmHg}$ and best eye mean visual acuity was 8.80 . The frequency of high compliance $(56.6 \%)$ was much greater than that of low compliance (22.1\%).

\section{Bayesian networks}

The BN (Figure 1) shows three nodes directly related to Travalert-identified compliance, ie, patient-clinician relationship, self-declared compliance, and age. Treatment concern has three drivers, which are disease concern, gender, and positive beliefs, and itself impacts on the patient-clinician relationship. Treatment convenience impacts on positive beliefs, which impacts upon self-declared compliance.

Two subgroups of patients had a noticeable distribution across groups defined according to treatment concern score (Table 2). First, women with a disease concern score $>47.018$ 
Table I Characteristics of patients included in the study $(n=169)$

\begin{tabular}{llll}
\hline Age, years & MD & I & \\
& Mean (SD) & 65.1 & $(1 \mathrm{I} .8)$ \\
& Median (range) & 67.5 & $(18-89)$ \\
Gender, n (\%) & MD & 1 & \\
& Male & 83 & $(49.1)$ \\
& Female & 85 & $(50.3)$ \\
Comorbidities, n (\%) & Ocular & 19 & $(11.2)$ \\
& Other & 50 & $(29.6)$ \\
Nonmedicated treatment & MD & 1 & \\
of glaucoma/intraocular & Surgery & 28 & $(16.6)$ \\
high pressure, n (\%) & Laser & 17 & $(10.1)$ \\
Intraocular pressure, mmHg & MD & 5 & \\
(worst eye) & Mean (SD) & 16.42 & $(3.87)$ \\
& Median (range) & 16 & $(9-40)$ \\
Visual acuity (best eye) & MD & 13 & \\
& Mean (SD) & 8.80 & $(1.98)$ \\
& Median (range) & 10 & $(1-12)$ \\
Compliance profiles, $n$ (\%) & MD & 56 & \\
& Low compliance & 25 & $(22.1)$ \\
& Moderate compliance & 24 & $(21.2)$ \\
& High compliance & 64 & $(56.6)$ \\
\hline
\end{tabular}

Note: a Decimal scale.

Abbreviations: MD, missing data; SD, standard deviation.

were markedly more likely to have a treatment concern score of $>24.197$ than the total population. Second, patients with a disease concern score of $<47.018$ and a positive beliefs score $>61.335$ were also more likely to have a treatment concern score of $>24.197$.
When compared with the total population, a higher percentage of patients with a treatment concern score $<24.197$ had a patient-clinician relationship score $>67.5$ (Table 3 ). More patients with a treatment convenience score of $<69.397$ had a positive beliefs score $<61.335$ compared with the total analysis population (Table 4). A higher percentage of patients with a positive beliefs score $<61.335$ had a self-declared compliance score $<89.583$, as compared with the analyzed population (Table 5).

Compliance identified by Travalert was related to three variables, these being age, patient-clinician relationship, and self-declared compliance (Table 6). Three different combinations of these characteristics were relevant to low or high compliance, compared with the total sample (Figure 2). Low compliance was associated with two combinations; first, age $<77.5$ years, a self-declared compliance score $<89.5$, and a patient-clinician relationship score $<67.5$ and, second, age $>77.5$ years, a self-declared compliance score of $>89.5$, and a patient-clinician relationship score $<67.5$. By contrast, high compliance was associated with age $<77.5$ years, a self-declared compliance score $>89.5$, and a patient-clinician relationship score $>67.5$.

\section{Discussion}

The primary objective of this study was to identify glaucoma patients who adhered poorly to treatment by recording their

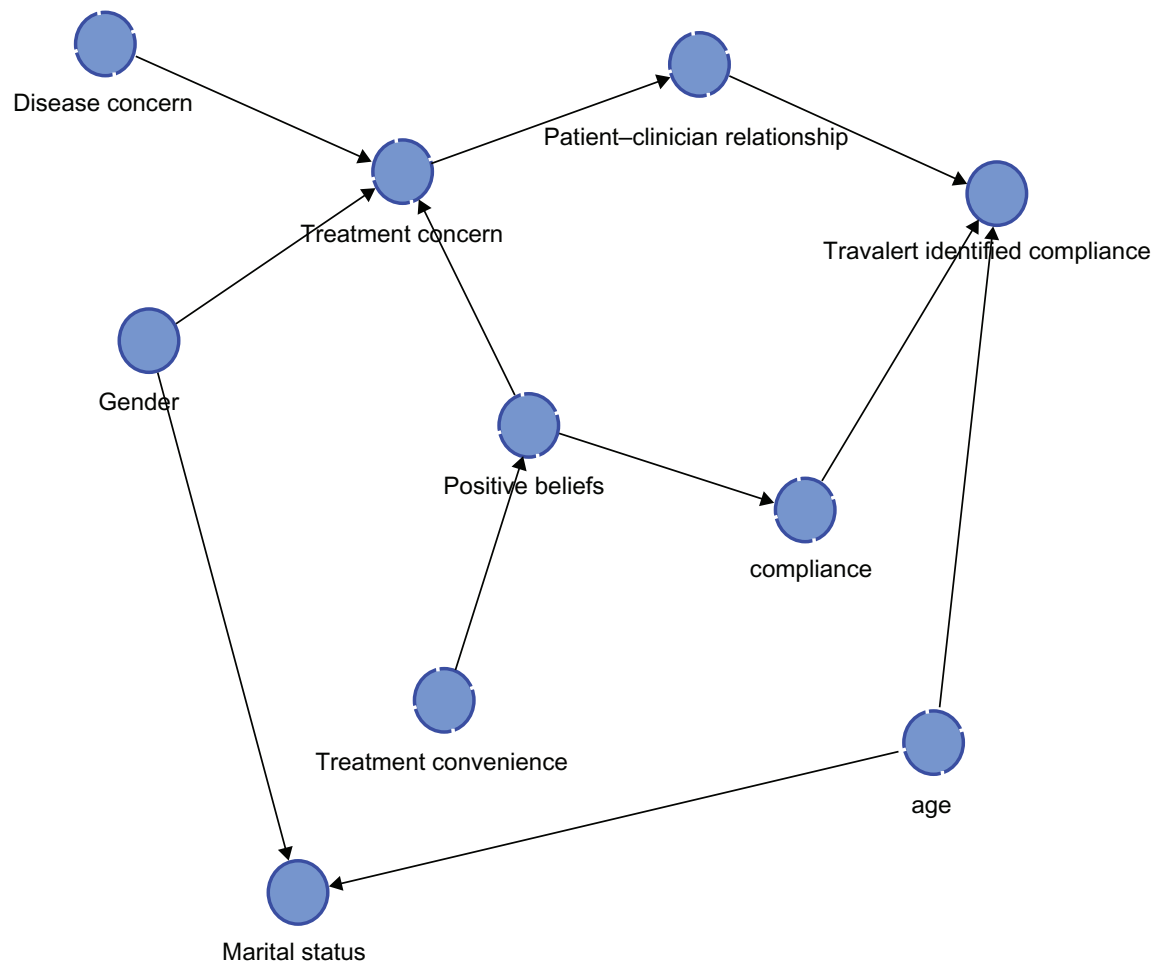

Figure I Bayesian network diagram predicting compliance as measured by Travalert ${ }^{\circledR}$, obtained by oversampling data. 
Table 2 Associations between treatment concern scores and positive beliefs scores, disease concern scores, and gender

\begin{tabular}{lllllll}
\hline $\begin{array}{l}\text { Positive } \\
\text { beliefs } \\
\text { score }\end{array}$ & $\begin{array}{l}\text { Disease } \\
\text { concern } \\
\text { score }\end{array}$ & & Gender & \multicolumn{2}{l}{$\begin{array}{l}\text { Treatment concern score } \\
\text { (n, \%) }\end{array}$} & \multicolumn{4}{l}{$\leq \mathbf{2 4 . 1 9 7}$} & \multicolumn{2}{l}{ 24.197 } \\
\hline$\leq 61.335$ & $\leq 47.018$ & Female & 5 & $(55.6)$ & 4 & $(44.4)$ \\
$\leq 61.335$ & $\leq 47.018$ & Male & 9 & $(60.0)$ & 6 & $(40.0)$ \\
$\leq 61.335$ & $>47.018$ & Female & 5 & $(31.3)$ & 11 & $(68.8)$ \\
$\leq 61.335$ & $>47.018$ & Male & 10 & $(52.6)$ & 9 & $(47.4)$ \\
$>61.335$ & $\leq 47.018$ & Female & 16 & $(88.9)$ & 2 & $(11.1)$ \\
$>61.335$ & $\leq 47.018$ & Male & $31.5^{\mathrm{a}}$ & $(85.1)$ & $5.5^{\mathrm{a}}$ & $(14.9)$ \\
$>61.335$ & $>47.018$ & Female & 13 & $(36.6)$ & $22.5^{\mathrm{a}}$ & $(63.4)$ \\
$>61.335$ & $>47.018$ & Male & 21 & $(79.2)$ & $5.5^{\mathrm{a}}$ & $(20.8)$ \\
Total & & & $110.5^{\mathrm{a}}$ & $(62.8)$ & $65.5^{\mathrm{a}}$ & $(37.2)$ \\
\hline
\end{tabular}

Notes: ${ }^{a} 0.5$ frequencies due to missing data imputation. Eye-Drop Satisfaction Questionnaire scores ranged from 0 to 100 . Higher dimension scores reflect more of the attribute implied by the name (eg, higher concern about disease). Threshold values fixed by the Bayesian network algorithm.

daily instillation times and eye drop counts objectively, with a computerized bottle holder (Travalert). In a previous analysis, patient demographics and baseline clinical parameters failed to discriminate between patients showing high, moderate, or low compliance. ${ }^{4}$ This second attempt enquired about attitudes towards treatment that might characterize poor compliers. This was explored with the EDSQ that examines patients' views about eye drop treatments, with aspects relevant to glaucoma, in order to explore compliance profiles. BN analysis was applied successfully to the EDSQ scores characterizing three compliance levels. The analysis identified two subgroups of patients at high risk of poor compliance when measured objectively; first, patients younger than 77.5 years of age with low self-declared compliance and an unsatisfactory relationship with their physician and, second, patients older than 77.5 years of age with high self-declared compliance and an unsatisfactory relationship with their physician.

These results confirm studies showing that communication and a good patient-physician relationship that provides

Table 3 Associations between patient-clinician relationship scores and treatment concern scores

\begin{tabular}{lllll}
\hline $\begin{array}{l}\text { Treatment concerns } \\
\text { score }\end{array}$ & \multicolumn{3}{l}{$\begin{array}{l}\text { Patient-clinician relationship } \\
\text { score }(\mathbf{n}, \%)\end{array}$} \\
\cline { 2 - 5 } & $\leq \mathbf{6 7 . 5}$ & & $>\mathbf{6 7 . 5}$ & \\
\hline$\leq 24.197$ & 9 & $(8.1)$ & $101.5^{\mathrm{a}}$ & $(91.9)$ \\
$>24.197$ & 24 & $(36.6)$ & $41.5^{\mathrm{a}}$ & $(63.4)$ \\
Total & 33 & $(18.8)$ & 143 & $(81.2)$ \\
\hline
\end{tabular}

Notes: 0.5 frequencies due to missing data imputation. Eye-Drop Satisfaction Questionnaire scores ranged from 0 to 100 . Higher dimension scores reflect more of the attribute implied by the name (eg, higher concern about treatment, a better clinician relationship). Threshold values fixed by the Bayesian network algorithm.
Table 4 Associations between positive beliefs scores and treatment convenience scores

\begin{tabular}{lllll}
\hline \multirow{2}{*}{$\begin{array}{l}\text { Treatment convenience } \\
\text { score }\end{array}$} & \multicolumn{3}{l}{ Positive beliefs score (n, \%) } \\
\cline { 2 - 5 } & $\leq 61.335$ & \multicolumn{3}{l}{$>61.335$} \\
\hline$\leq 69.397$ & $38.5^{\mathrm{a}}$ & $(51.0)$ & 37 & $(49.0)$ \\
$>69.397$ & $20.5^{\mathrm{a}}$ & $(20.4)$ & 80 & $(79.6)$ \\
Total & 59 & $(33.5)$ & 117 & $(66.5)$ \\
\hline
\end{tabular}

Notes: ${ }^{a} 0.5$ frequencies due to missing data imputation. Eye-Drop Satisfaction Questionnaire scores ranged from 0 to 100. Higher dimension scores reflect more of the attribute implied by the name. Threshold values fixed by the Bayesian network algorithm.

education for patients about glaucoma and its treatment is essential for compliance. , $^{811-13,16}$ Conversely, because patients rely strongly on their doctor for such information, a poor relationship was identified as a major barrier to compliance. ${ }^{8,11,12,16-18}$

Interestingly, our results are not fully consistent with previous publications with respect to age and other factors associated with compliance. First, we found a relationship between age and compliance that was not observed in several studies. ${ }^{11,14,18,20,34}$ However, in contrast with customary statistical methods, we used BN based on association tables and inevitably model interaction effects between variables. Consequently, age was included with other factors (patientclinician relationship and self-declared compliance), and was thereby related to objectively identified compliance (Travalert). Methods used in previous work may not have revealed such interaction effects.

Second, trust in the efficacy of treatment (closely related to our positive beliefs score) has been previously related to compliance, ${ }^{8,12}$ as have been concerns about disease ${ }^{5}$ and treatment convenience. ${ }^{12,34}$ Our BN analysis linked no equivalent EDSQ item directly to compliance. This difference may be explained by specific features of $\mathrm{BN}$.

In our study, the absence of direct links between Travalertidentified compliance and previously identified components of compliance can be explained by the notion of conditional independence. The finding that only age, self-declared compliance scores, and patient-clinician relationship scores were

Table 5 Associations between declared compliance scores and positive beliefs scores

\begin{tabular}{lllll}
\hline Positive beliefs score & \multicolumn{4}{l}{ Declared compliance score (n, \%) } \\
\cline { 2 - 5 } & $\leq \mathbf{8 9 . 5 8 3}$ & \multicolumn{4}{c}{$>\mathbf{8 9 . 5 8 3}$} \\
\hline$<=61.335$ & 31 & $(52.5)$ & 28 & $(47.5)$ \\
$>61.335$ & 18 & $(15.4)$ & 99 & $(84.6)$ \\
Total & 49 & $(27.8)$ & 127 & $(72.2)$ \\
\hline
\end{tabular}

Notes: Eye-Drop Satisfaction Questionnaire scores ranged from 0 to 100. Higher dimension scores reflect more of the attribute implied by the name. Threshold values fixed by the Bayesian network algorithm. 
Table 6 Associations between Travalert ${ }^{\circledR}$ identified compliance and self-declared compliance scores, patient-clinician relationship scores, and age

\begin{tabular}{|c|c|c|c|c|c|c|}
\hline \multirow{3}{*}{$\begin{array}{l}\begin{array}{l}\text { Self-declared } \\
\text { compliance score }\end{array} \\
\leq 89.583\end{array}$} & \multirow{3}{*}{$\begin{array}{l}\text { Age } \\
\leq 77.5\end{array}$} & \multirow{3}{*}{$\begin{array}{l}\text { Patient-clinician } \\
\text { relationship score }\end{array}$} & \multicolumn{4}{|c|}{ Travalert identified compliance (n, \%) } \\
\hline & & & \multicolumn{2}{|c|}{ Low } & \multicolumn{2}{|c|}{ Moderate/high } \\
\hline & & & 7 & $(87.5)$ & 1 & $(12.5)$ \\
\hline$\leq 89.583$ & $\leq 77.5$ & $>67.5$ & 24 & $(66.7)$ & 12 & $(33.3)$ \\
\hline$\leq 89.583$ & $>77.5$ & $\leq 67.5$ & 0 & $(0.0)$ & $0.5^{\mathrm{a}}$ & $(100.0)$ \\
\hline$\leq 89.583$ & $>77.5$ & $>67.5$ & 3 & $(66.7)$ & $1.5^{\mathrm{a}}$ & $(33.3)$ \\
\hline$>89.583$ & $\leq 77.5$ & $\leq 67.5$ & 8 & $(55.2)$ & $6.5^{\mathrm{a}}$ & $(44.8)$ \\
\hline$>89.583$ & $\leq 77.5$ & $>67.5$ & 19 & $(24.7)$ & 58 & $(75.3)$ \\
\hline$>89.583$ & $>77.5$ & $\leq 67.5$ & 10 & $(100.0)$ & 0 & $(0.0)$ \\
\hline$>89.583$ & $>77.5$ & $>67.5$ & 17 & $(66.7)$ & $8.5^{\mathrm{a}}$ & (33.3) \\
\hline Total & & & 88 & $(50.0)$ & 88 & $(50.0)$ \\
\hline
\end{tabular}

Notes: ${ }^{a} 0.5$ frequencies are due to missing data imputation. Eye-Drop Satisfaction Questionnaire scores ranged from 0 to 100 . Higher dimension scores reflect more of the attribute implied by the name. Threshold values fixed by the Bayesian network algorithm.

linked directly to compliance indicates that compliance was conditionally independent of other $\mathrm{BN}$ variables. It does not mean that other variables were not involved in compliance indirectly. In fact, $\mathrm{BN}$ showed these scores to be indirect components of compliance by linkage through other variables. Thus, BN may provide a more precise description of the compliance process, and may show how different conceptions of compliance, finally impact on the behavior of glaucoma patients.

This study applied advanced techniques for data analysis, ie, BN and oversampling. The rationale for BN was that patients' satisfaction and compliance with treatment is a multidimensional phenomenon calling for methods that take complexity into account. Also, an oversampling strategy had to be introduced. The numeric imbalance between compliant patients and poorly compliant patients jeopardized the quality of our results, so we considered possible simple solutions to the problem, ie, oversampling (artificially increasing the size of the smallest group by random sampling and replacement), and undersampling (reducing the size of the largest group by randomly deleting cases). Despite evidence that undersampling has previously shown better results ${ }^{35,36}$ and that oversampling may increase the risk of overfitting, ${ }^{37}$ the latter method had to be used because of our very small dataset, ie, only 113 patients

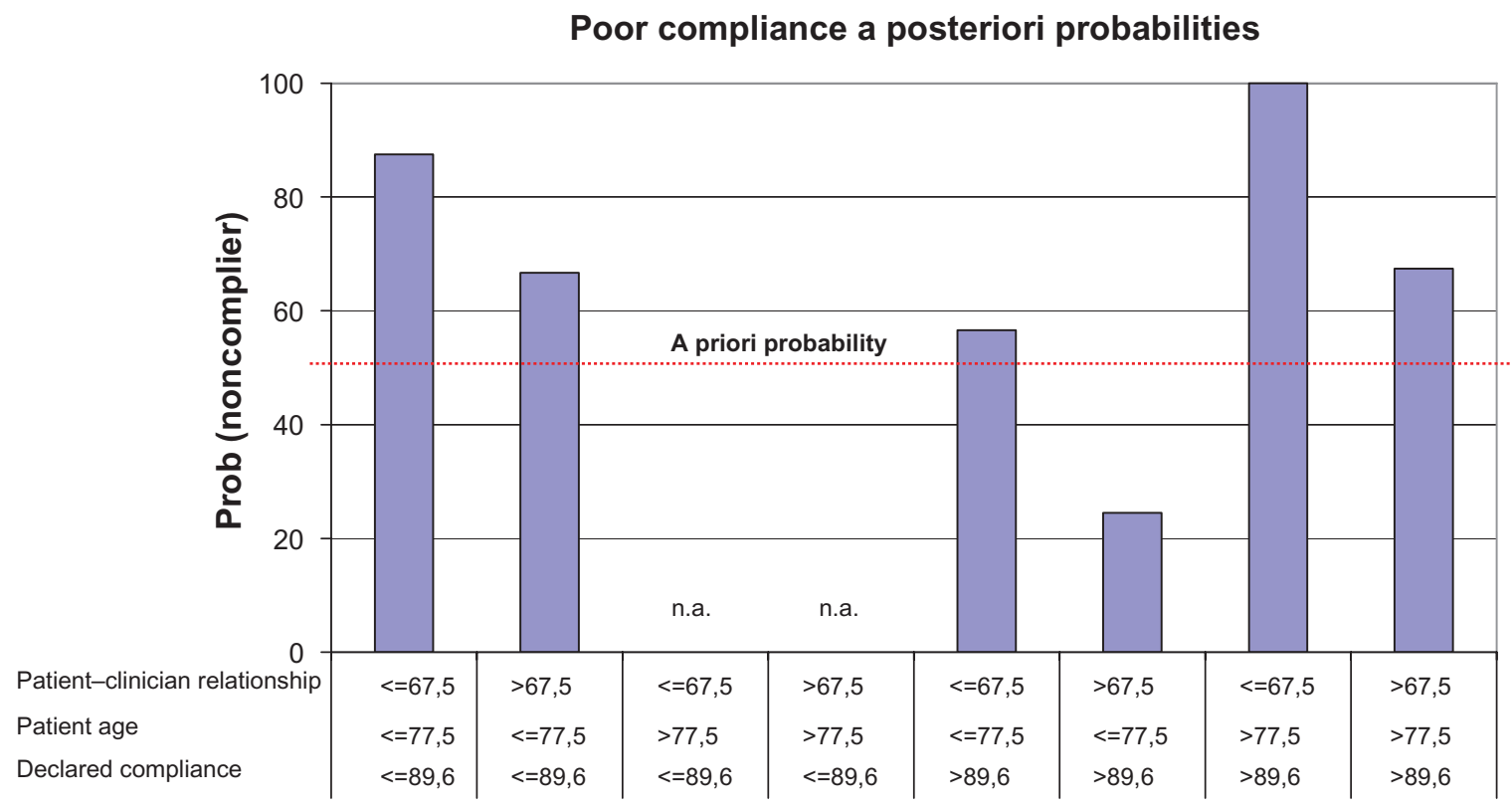

Figure 2 A posteriori probabilities of low compliance, according to age, patient-clinician relationship, and self-declared compliance. A priori probability was fixed at $50 \%$ as the result of the over sampling. Blue vertical bars represents a posteriori probabilities, once EDSQ results were estimated. The greater the distance from the red line to the bar chart, the greater the BN added value at determining patient compliance. EDSQ scores ranged from 0 to 100 . Higher dimension scores reflect more of the attribute implied by the name. Threshold values fixed by the BN algorithm.

Abbreviation: n.a., not applicable. 
provided sufficient data to construct a compliance profile, and the low-compliance group included only 25 patients.

The age and gender ratios of our sample are close to those of glaucoma-treated patients in France. ${ }^{38}$ Whether these results could apply to other countries (within or even outside the European Union) is debatable, especially when some factors appeared to be culture-dependent, such as confidence in the doctor. Also, economic factors might play a role in this older population. For example, reimbursement status in France is almost independent of retirement, which is not the case in other countries. On the one hand, the EDSQ was developed according to a conceptual model and it was tested that this model applied in other countries. On the other hand, patient data collection will be requested to check whether this hypothesis will remain empirically valid.

We acknowledge that our study has certain limitations. First, our analyses were performed on a relatively small number of patients. Thus, the BN structure may have been biased by a few noncompliers. Also, only 113 (63.1\%) patients of 179 were investigated for both EDSQ and compliance, possibly leading to selection bias, although internal validity (explored by the $\mathrm{BN}$ ) might be less affected. We have not performed sample size estimation for a protocol aimed at confirming our findings without using the oversampling method. Microsimulation based on the BN described and accounting for the prevalence of poor compliance might be useful to fix the size of a future experiment. Second, we followed up patients who were willing to use Travalert, and these patients might have different behavior from that of the general population. Third, the results reported were observed in patients treated either by Travatan ${ }^{\circledR}$ or DuoTrav ${ }^{\circledR}$, so extrapolation of the $\mathrm{BN}$ results to other drugs needs to be documented. Fourth, only one approach was adopted to elicit a BN structure. The small sample size of our survey did not allow for a test-retest-validation process. Hence, the resulting structure should be viewed with caution, and new surveys should be conducted to validate our findings. Also, it might well be worthwhile to undertake a validation of the structure, replicating our analysis with other structural learning algorithms and larger datasets. Finally, a question must be raised concerning our objective assessment of compliance. Electronic devices have been recognized as an efficient way to assess compliance, ${ }^{19}$ but they may have limitations. In particular, one reason for poor compliance encountered by some patients is difficulty with instilling eye drops correctly. ${ }^{13,18}$ Because Travalert counts only the number of drops dispensed by a bottle, and cannot verify that they are correctly instilled, our study could not control this aspect of the research. Moreover, patients knew they were being observed, which might have impacted on their behavior. However, in a previous paper, we reported that these poor compliers had a significant increase in IOP (by about $2 \mathrm{mmHg}$ ) in comparison with good compliers. Therefore, this observational bias might have underestimated the impact of compliance on IOP control. Consequently, this BN identified poor compliers who had a lack of IOP control of at least $2 \mathrm{mmHg}$, which is a clinically relevant difference. Our sample size was not big enough to explore both the impact of clinician and patient characteristics on identifying poor compliers. In this approach, we favored data collected at a patient level. Additional research might be useful for identifying the correct information to be collected at an ophthalmologist level. These limitations warrant a cautious interpretation of our results and further work with a larger sample size and test-retest methodology to confirm the findings.

\section{Conclusion}

In conclusion, the application of BN to EDSQ data made it possible to re-examine the complex process of treatment compliance in glaucoma patients and to identify reasons for poor compliance. The crucial message for physicians from our results is that, before switching glaucoma treatments because of poor IOP control, they should consider the patient's age, self-declared compliance, and how best to educate the patient about glaucoma and its treatment.

\section{Acknowledgments}

This survey was supported by an unrestricted grant from Alcon France SA, Rueil-Malmaison, France. The analysis was performed by Mapi Values, Lyon, France. Dr Gilles Berdeaux is employed by Alcon France. Pr Nordmann, Pr Baudouin, Pr Renard, and Pr Denis have participated in clinical trials sponsored by Alcon and are appointed as clinical experts. We would like to thank Dr Robert Pigache for his editorial assistance with this work.

\section{Disclosure}

The authors report no conflicts of interest in this work.

\section{References}

1. Resnikoff S, Pascolini D, Etya'ale D, et al. Global data on visual impairment in the year 2002. Bull World Health Organ. 2004;82: 844-851.

2. Lee PP, Feldman ZW, Ostermann J, Brown DS, Sloan FA. Longitudinal prevalence of major eye diseases. Arch Ophthalmol. 2003;121: 1303-1310.

3. European Glaucoma Society. Terminology and Guidelines for Glaucoma 3rd ed. 2008. Available from: http://www.eugs.org/eng/EGS_guidelines. asp. Accessed 2010 Sep 17. 
4. Nordmann JP, Baudouin C, Renard JP, et al. Measurement of treatment compliance using a medical device for glaucoma patients associated with intraocular pressure control: A survey. Clin Ophthalmol. 2010;4: 731-739.

5. Forsman E, Kivela T, Vesti E. Lifetime visual disability in open-angle glaucoma and ocular hypertension. J Glaucoma. 2007;16:313-319.

6. Nordmann JP, Auzanneau N, Ricard S, Berdeaux G. Vision related quality of life and topical glaucoma treatment side effects. Health Qual Life Outcomes. 2003;1:75.

7. Friedman DS, Quigley HA, Gelb L, et al. Using pharmacy claims data to study adherence to glaucoma medications: Methodology and findings of the Glaucoma Adherence and Persistency Study (GAPS). Invest Ophthalmol Vis Sci. 2007;48:5052-5057.

8. Friedman DS, Hahn SR, Gelb L, et al. Doctor-patient communication, health-related beliefs, and adherence in glaucoma results from the Glaucoma Adherence and Persistency Study. Ophthalmology. 2008; 115:1320-1327.

9. Quigley HA, Friedman DS, Hahn SR. Evaluation of practice patterns for the care of open-angle glaucoma compared with claims data: The Glaucoma Adherence and Persistency Study. Ophthalmology. 2007; 114:1599-1606.

10. Kass MA, Meltzer DW, Gordon M. A miniature compliance monitor for eyedrop medication. Arch Ophthalmol. 1984;102:1550-1554.

11. Spaeth GL. Visual loss in a glaucoma clinic. I. Sociological considerations. Invest Ophthalmol. 1970;9:73-82.

12. Lacey J, Cate H, Broadway DC. Barriers to adherence with glaucoma medications: A qualitative research study. Eye (Lond). 2009;23: 924-932.

13. Winfield AJ, Jessiman D, Williams A, Esakowitz L. A study of the causes of non-compliance by patients prescribed eyedrops. Br J Ophthalmol. 1990;74:477-480.

14. Bour T, Blanchard F, Segal A. Epidemiological data on primary open-angle glaucoma and treatment in the department of Marne. J Fr Ophtalmol. 1993;16:367-379. French.

15. Day DG, Sharpe ED, Atkinson MJ, Stewart JA, Stewart WC. The clinical validity of the treatment satisfaction survey for intraocular pressure in ocular hypertensive and glaucoma patients. Eye (Lond). 2006;20:583-590.

16. Deokule S, Sadiq S, Shah S. Chronic open angle glaucoma: Patient awareness of the nature of the disease, topical medication, compliance and the prevalence of systemic symptoms. Ophthalmic Physiol Opt. 2004;24:9-15.

17. Herndon LW, Brunner TM, Rollins JN. The glaucoma research foundation patient survey: Patient understanding of glaucoma and its treatment. Am J Ophthalmol. 2006;141:S22-S27.

18. Konstas AG, Maskaleris G, Gratsonidis S, Sardelli C. Compliance and viewpoint of glaucoma patients in Greece. Eye (Lond). 2000;14 Pt 5: $752-756$.

19. Claxton AJ, Cramer J, Pierce C. A systematic review of the associations between dose regimens and medication compliance. Clin Ther. 2001; 23:1296-1310.

20. Gurwitz JH, Glynn RJ, Monane M, et al. Treatment for glaucoma: Adherence by the elderly. Am J Public Health. 1993;83:711-716.

21. Wilensky J, Fiscella RG, Carlson AM, et al. Measurement of persistence and adherence to regimens of IOP-lowering glaucoma medications using pharmacy claims data. Am J Ophthalmol. 2006;141:S28-S33.

Clinical Ophthalmology

\section{Publish your work in this journal}

Clinical Ophthalmology is an international, peer-reviewed journal covering all subspecialties within ophthalmology. Key topics include: Optometry; Visual science; Pharmacology and drug therapy in eye diseases; Basic Sciences; Primary and Secondary eye care; Patient Safety and Quality of Care Improvements. This journal is indexed on Submit your manuscript here: http://www.dovepress.com/clinical-ophthalmology-journal
22. Robin AL, Covert D. Does adjunctive glaucoma therapy affect adherence to the initial primary therapy? Ophthalmology. 2005;112:863-868.

23. Nordmann JP, Denis P, Vigneux M, et al. Development of the conceptual framework of the Eye-Drop Satisfaction Questionnaire (EDSQ) in glaucoma using a qualitative study. BMC Health Serv Res. 2007; $7: 124$.

24. Directive 2001/20/EC of the European parliament and of the council of 4 Apr 2001. Avaiable from: http://eur-lex.europa.eu/smartapi/cgi/ sga_doc?smartapi!celexapi!prod!CELEXnumdoc\&lg=en\&numdoc= 32001L0020\&model=guicheti. Accessed 2010 Sep 17.

25. Comité consultatif sur le traitement de l'information en matière de recherche dans le domaine de la santé. Available from: http://www. enseignementsup-recherche.gouv.fr/cid20537/cctirs.html. Accessed 2010

26. La commission nationale de l'informatique et des libertés. Available from: http://www.cnil.fr/. Accessed 2010.

27. Declaration of Helsinki. World Medical Association. Available from: http://www.wma.net/e/ethicsunit/helsinki.htm. Accessed on 2010 Sep 17.

28. Boden C, Sit A, Weinreb RN. Accuracy of an electronic monitoring and reminder device for use with travoprost eye drops. J Glaucoma. 2006;15:30-34.

29. Friedman DS, Jampel HD, Congdon NG, Miller R, Quigley HA. The Travatan Dosing Aid accurately records when drops are taken. Am J Ophthalmol. 2007;143:699-701.

30. Regnault A, Viala-Danten M, Gilet H, Berdeaux G. Scoring and psychometric properties of the Eye-Drop Satisfaction Questionnaire (EDSQ), an instrument to assess satisfaction and compliance with glaucoma treatment. BMC Ophthalmology. 2010;10:1.

31. Kotsiantis S, Kanellopoulos D, Pintelas P. Handling imbalanced datasets: A review. GESTS International Transactions on Computer Science and Engineering. 2006:25-36.

32. Friedman N, Goldszmidt M. Learning Bayesian networks with local structure. Proceedings of the Twelfth Conference on Uncertainty in Artificial Intelligence. San Francisco, CA: Morgan Kaufman; 1996.

33. Glover F, Laguna M. Tabu Search. Boston MA: Kluwer Academic Publisher; 1997.

34. Patel SC, Spaeth GL. Compliance in patients prescribed eyedrops for glaucoma. Ophthalmic Surg. 1995;26:233-236.

35. Drummond C, Holte RC. C4.5, Class imbalance and cost sensitivity: Why under-sampling beats over-sampling. 2003. Available from: http:// www.site.uottawa.ca/ nat/Workshop2003/drummondc.pdf. Accessed 2010 Sep.

36. Japkowicz N. The class imbalance problem: Significance and strategies. In: Proceedings of the 2000 International Conference on Artificial Intelligence. Las Vegas, NV: CSREA Press; 2000.

37. Chawla NV, Bowyer KW, Hall LO, Kegelmeyer WP. SMOTE: Synthetic minority over-sampling technique. J Artif Intell Res. 2002; 16:321-357.

38. Kobelt G, Texier-Richard B, Buchholz P, et al. Treatment of glaucoma in clinical practice: Four-year results from a patient registry in France. J Glaucoma. 2009 Aug 5. [Epub ahead of print].

\section{Dovepress}

PubMed Central and CAS, and is the official journal of The Society of Clinical Ophthalmology (SCO). The manuscript management system is completely online and includes a very quick and fair peer-review system, which is all easy to use. Visit http://www.dovepress.com/ testimonials.php to read real quotes from published authors. 